\title{
Foreign Body Ethmoid: An Unusual Presentation
}

\author{
${ }^{1}$ Vikas Kakkar, ${ }^{2}$ Shehbaaz Singh Virk, ${ }^{3}$ Chandni Sharma, ${ }^{4}$ Priya Malik, ${ }^{5}$ Surender Bishnoi, ${ }^{6}$ Ankit Gulati
}

\begin{abstract}
A patient with $8 \mathrm{~cm}$ long penetrating wooden foreign body in the left ethmoid which was lying along the long-axis of ethmoid is presented. It was successfully managed. Investigation and management strategy is discussed.
\end{abstract}

Keywords: Foreign body, Ethmoid, Unusual, Removal.

How to cite this article: Kakkar V, Virk SS, Sharma C, Malik P, Bishnoi S, Gulati A. Foreign Body Ethmoid: An Unusual Presentation. Clin Rhinol An Int J 2014;7(3):130-131.

\section{Source of support: Nil}

Conflict of interest: None

\section{INTRODUCTION}

Foreign bodies of the nasal cavity are relatively frequent in pediatric patients, while in the adults, they are usually seen in disturbed persons or at the emergency room. They include representative cases of the most commonly encountered types of these injuries: industrial accident and criminal assault.

Immediate radiological examination is mandatory because deceptively small entrance wound is usually in no way commensurate with the large size of the foreign body, the presence of which is frequently not suspected. The surgical removal of these foreign bodies requires careful preoperative assessment to avoid undue injury to the surrounding vital structures like orbit and cribriform plate. ${ }^{1}$

\section{CASE REPORT}

A 24-year-old male patient presented to PGIMS, Rohtak casualty in evening with history of fall from motor bike that morning when he lost control of the bike and landed up in the bushes on the road side, following which he had a solo injury near medial canthus of the left eye on nasal bridge. A linear laceration wound of about $2 \mathrm{~cm}$

\footnotetext{
${ }^{1}$ Professor, ${ }^{2,3}$ Senior Resident, ${ }^{4-6}$ Postgraduate Student

${ }^{1-6}$ Department of Otorhinolaryngology, Post Graduate Institute of Medical Sciences, Rohtak, Haryana, India
}

Corresponding Author: Chandni Sharma, Senior Resident Department of Otorhinolaryngology, Post Graduate Institute of Medical Sciences, Rohtak, Haryana, India, e-mail: drchandni13ent@gmail.com wide was present from which about $1 \mathrm{~cm}$ wooden piece was protruding out. Patient gave history that multiple unsuccessful attempts were made by some local doctor outside before presenting to our casualty. ENT and ophthalmologist opinion were obtained in the casualty. On examination, a $2 \mathrm{~cm}$ linear cut below and medial to left medial canthus with a protruding wooden stick was present. Eye movements, vision and fundus examination were normal. No active bleeding from the wound and the nose was present. Patient was admitted in ENT ward for detailed evaluation and removal.

Preoperatively, CT scan was done showing foreign body in posterior ethmoidal sinus parallel to the left lamina papyracea.

CT scan showing radiolucent foreign body penetrating the ethmoid sinus (Fig. 1).

Patient was taken to the operation theater next day and diagnostic nasal endoscopy was done which revealed all three turbinates and meatus were normal with no mucopus or blood stained discharge. Under general anesthesia, foreign body was pulled out using straight artery forcep slowly which was $8 \mathrm{~cm}$ long and 5 to $6 \mathrm{~mm}$ in diameter (Fig. 2).

Intra- and postoperative period was uneventful. Patient was discharged on tablet antibiotics and NSAIDS for 5 days.

\section{DISCUSSION}

If these foreign bodies are radiopaque, then these can be easily recognizable by $\mathrm{X}$-ray. However to know the

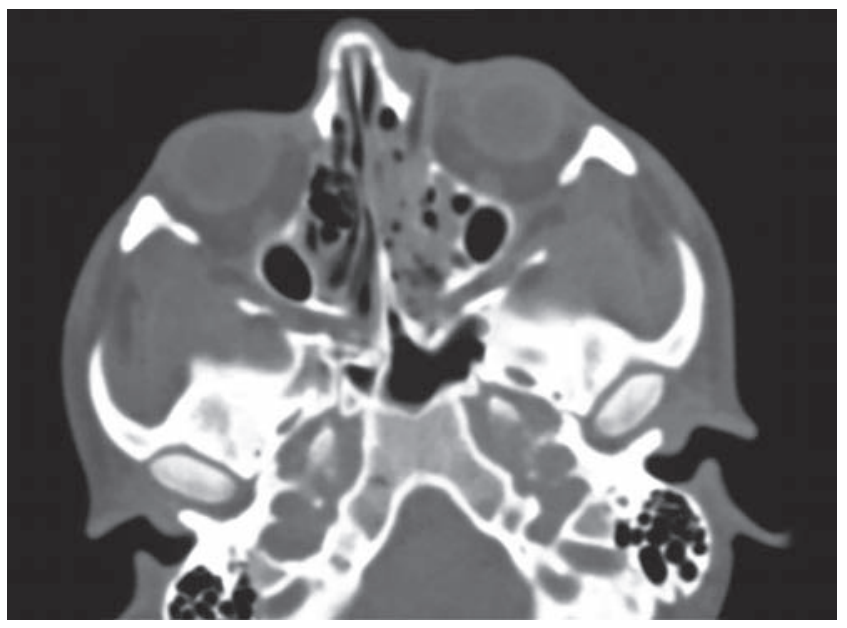

Fig. 1: CT scan showing radiolucent foreign body penetrating the ethmoid sinus 


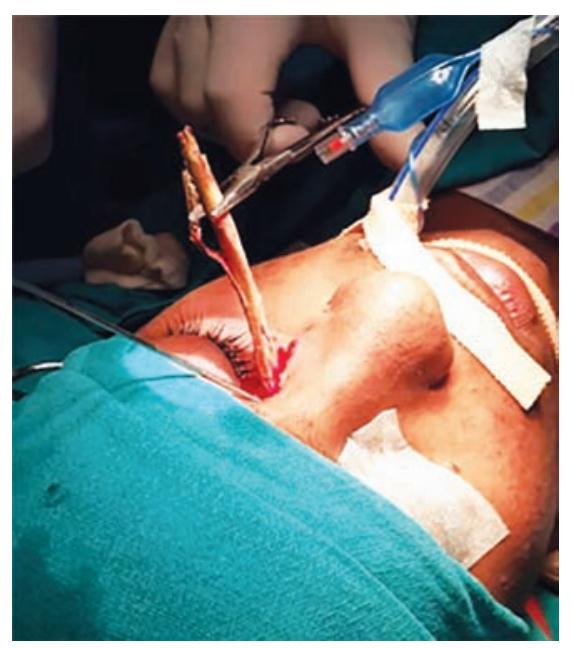

Fig. 2: Removal of $8 \mathrm{~cm}$ long wooden foreign body entering the left ethmoid sinus

exact extent of damage caused by these foreign bodies $\mathrm{CT}$ scan is must. If foreign body is large then removal is not easy by routine endoscopy. The structure like optic nerve, carotid artery, cribriform plate and orbit itself lies in close relation to these sinuses. ${ }^{2,6,5}$

A foreign sharp body, such as the one presented here, must be carefully handled, evaluating criteria such as the integrity of the skin, the number of skeleton interruptions, the involvement of the joints, the gravity of the injuries and of the possible damage to the soft tissues, vascular structures and nerves. ${ }^{3}$
The management of such cases should be conservative unless any one of the following complications occur: (1) severe inflammation (abscess, cellulitis, fistula); (2) compressive effects on the eye and (3) communication of the orbit with the paranasal sinuses or intracranial space. Further a careful localization of the foreign body should be done with all possible investigations including $\mathrm{CT}$ and MRI before attempting surgical removal so as to avoid damage to important structures. Another reason is that many foreign bodies, particularly organic and wooden ones, fragment easily during surgical removal, leaving behind splinters that cause inflammation and foreign body granuloma even after long quiescent period. ${ }^{4}$

\section{REFERENCES}

1. Bakay L, Glasauer FE, Grand W. Unusual intracranial foreign bodies. Acta Neurochirurgica 1977;39(3-4):219-231.

2. Sharma R, Minhas R, Mohindroo N. An unusual foreign body in paranasal sinuses. Ind J Otolaryngol Head Neck Surg 2008;60(1):88-90.

3. Pellacchia V, Moricca LM, Buonaccorsi S, Indrizzi E, Fini G. Unusual foreign body in the nasal cavity. J Craniofac Surg 2006;17(6):1176-1180.

4. Agarwal PK, Kumar H, Srivastava PK. Unusual orbital foreign bodies. Ind J Ophthalmol 1993;41(3):125-127.

5. Datta H, Sarkar K, Chatterjee PR, Kundu A. An unusual case of retained metallic arrow head in the orbit and sphenoid sinus. Ind J Ophthalmol 2001;49(3):197-198.

6. Singh V, Kaur A, Agrawal S. An unusual intraorbital foreign body. Ind J Ophthalmol 2004;52(1):64-65. 